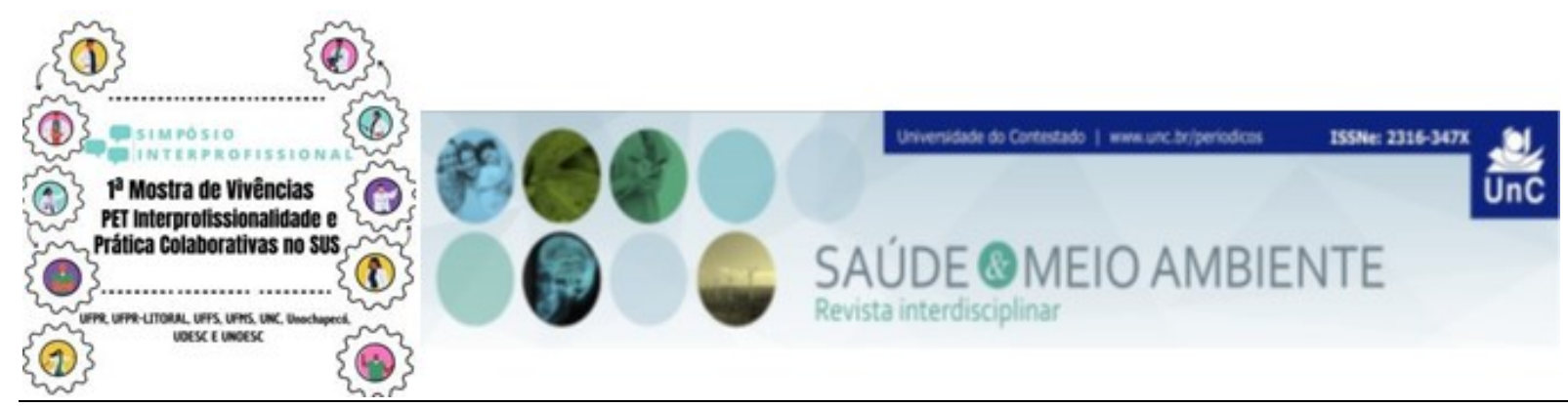

\title{
O PET-SAÚDE/INTERPROFISSIONALIDADE COMO ESPAÇO FACILITADOR PARA A APRENDIZAGEM INTERPROFISSIONAL ${ }^{1}$
}

\author{
Projeto 140 - SESAU Chapecó-SC/UFFS/UDESC/UNOESC \\ Heloisa Schatz Kwiatkowiski² \\ Angela Makeli Kososki Dalagnol ${ }^{3}$ \\ Matheus Pelinski da Silveira ${ }^{4}$ \\ Larissa Gabriella Schneider ${ }^{5}$ \\ Marta Kolhs ${ }^{6}$ \\ Débora Tavares de Resende e Silva ${ }^{7}$
}

\begin{abstract}
RESUMO
Introdução: O Programa de Educação pelo Trabalho para a Saúde (PET-Saúde) Interprofissionalidade objetiva promover e qualificar a integração ensino-serviçocomunidade, envolvendo docentes, discentes e profissionais de saúde. Assim, Instituições de Ensino Superior de Chapecó junto à Secretaria de Saúde foram contempladas com o projeto. Entende-se a importância deste pois a própria Estratégia Saúde da Família prevê a associação de preceitos da Atenção Primária à Saúde com a interprofissionalidade ${ }^{1}$. Destaca-se neste projeto o alinhamento com os princípios da Educação Interprofissional (EIP), que prima, dentre outras coisas, pela Aprendizagem Interprofissional (AIP). Objetivo: Relatar a experiência de uma atividade com foco na AIP, em um Centro de Saúde da Família da região Oeste de Santa Catarina. Metodologia: A atividade foi realizada para o reconhecimento do território, e desenvolvida com petianos e Agentes Comunitários de Saúde (ACS) correspondentes ao território. Assim, o grupo dividiu-se de forma multiprofissional e direcionou cada subgrupo a um ACS. Durante a atividade, os petianos observaram, além da rotina do ACS, suas percepções sobre aquele território e comunidade.
\end{abstract}

${ }^{1}$ Fonte de financiamento: Programa de Educação pelo Trabalho para a Saúde - PET Saúde/Interprofissionalidade 2019-2021 (Edital no 10 de 23 de julho de 2018, Ministério da Saúde/Secretaria de Gestão do Trabalho e da Educação na Saúde).

${ }^{2}$ Acadêmica voluntária. Discente do Curso de Graduação em Enfermagem na Universidade Federal da Fronteira Sul. Santa Catarina. Brasil. E-mail: heloisa.kwiatkowiski@estudante.uffs.edu.br

${ }^{3}$ Acadêmica bolsista. Discente do Curso de Graduação em Enfermagem na Universidade Federal da Fronteira Sul. Santa Catarina. Brasil. E-mail: angeladalagnol8@gmail.com

${ }^{4}$ Acadêmico bolsista. Discente do Curso de Graduação em Medicina na Universidade Federal da Fronteira Sul. Santa Catarina. Brasil. E-mail: matheuspelinski@gmail.com

${ }^{5}$ Acadêmica bolsista. Discente do Curso de Graduação em Enfermagem na Universidade do Estado de Santa Catarina. Santa Catarina. Brasil. E-mail: lari gschneider@outlook.com

${ }^{6}$ Tutora. Docente do curso de Graduação em Enfermagem na Universidade do Estado de Santa Catarina. Santa Catarina. Brasil. E-mail: martakolhs@gmail.com

${ }^{7}$ Coordenadora. Docente adjunta dos cursos de Enfermagem e Medicina na Universidade Federal da Fronteira Sul. Santa Catarina. Brasil. E-mail: debora.silva@uffs.edu.br 
Voltando à Unidade, os grupos se reuniram para discutir as experiências, bem como trocar saberes acerca da atividade. Resultados: A partir do olhar do ACS, os subgrupos notaram dificuldades territoriais no que compete à infraestrutura urbana e de moradia, identificando características comuns às microáreas visitadas, que são influenciadoras no processo saúde-doença daquela comunidade. Nesta forma de imersão, os petianos estiveram inseridos no cenário de prática à luz da Educação Interprofissional, momento em que discentes de diferentes graduações realizaram troca de saberes com o ACS, consolidando a AIP. Tal aprendizagem apresenta forte potencial de resultar em melhores atitudes interprofissionais e de trabalho em equipe, visto que proporciona aos integrantes a possibilidade de enxergar o território e o serviço com os olhos de outros profissionais ${ }^{2}$. Desta forma, a AIP caracteriza-se uma importante estratégia para a formação profissional, pois, além de fortalecer as práticas colaborativas, potencializa a formação de futuros profissionais de saúde, fornecendoIhes o suporte necessário para uma assistência qualificada. Considerações Finais: Diante do exposto, percebe-se o PET-Saúde/Interprofissionalidade como facilitador para a AIP, evidenciado pela ação supracitada, o que corrobora com os objetivos do projeto. Além do fortalecimento da formação em saúde, fica explícito que atividades pautadas na EIP exercem papel significativo no Sistema Único de Saúde, pois melhoram o ambiente de trabalho, qualificam a assistência e permitem o crescimento profissional e pessoal dos envolvidos.

Palavras-chave: Colaboração Intersetorial. Ensino. Sistema Único de Saúde. Estratégia Saúde da Família. Aprendizagem.

\section{REFERÊNCIAS}

1. Ceccim RB. Connections and boundaries of interprofessionality: form and formation. Interface (Botucatu) [acesso em 08 ago 2020]. 2018; 22(2):1739-1749. Disponível em: https://doi.org/10.1590/1807-57622018.0477

2. Toassi RFC, Olsson TO, Lewgoy AMB, Bueno D, Peduzzi M. Ensino da graduação em cenários da atenção primária: espaço para aprendizagem interprofissional. Trabalho, Educação e Saúde (Rio de Janeiro) [acesso em 09 ago 2020]. 2020;18(2): e0026798. Disponível em: https://doi.org/10.1590/1981-7746-sol00267 